\title{
Current and cumulative night shift work and subclinical atherosclerosis: results of the Gutenberg Health Study
}

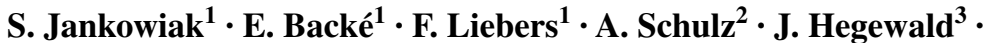 \\ S. Garthus-Niegel ${ }^{3,4} \cdot$ M. Nübling ${ }^{5}$ S. Blankenberg ${ }^{6} \cdot$ N. Pfeiffer ${ }^{7} \cdot$ K. J. Lackner ${ }^{8}$.

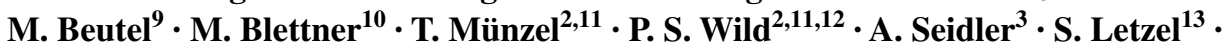 \\ U. Latza ${ }^{1}$
}

Received: 16 November 2015 / Accepted: 22 June 2016 / Published online: 5 July 2016

(C) The Author(s) 2016. This article is published with open access at Springerlink.com

\begin{abstract}
Purpose The study examines the association between exposure to current and cumulative night shift work and subclinical parameters of atherosclerosis.

Methods Participants of a population-based cohort study (the Gutenberg Health Study, $N=15,010$ ) aged 35-64 years were examined at baseline (2007-2012). Investigations included measurements of arterial stiffness, vascular function [reactive hyperaemia (RH) index], and intima media thickness (IMT). Also, a complete job history (including up to 15 periods), occupational exposures,
\end{abstract}

\section{U. Latza}

latza.ute@baua.bund.de

1 Division Work and Health, Federal Institute for Occupational Safety and Health (BAuA), Noeldnerstr. 40-42, 10317 Berlin, Germany

2 Preventive Cardiology and Preventive Medicine, Department of Medicine 2, University Medical Center Mainz, Johannes Gutenberg University Mainz, Langenbeckstr. 1, 55131 Mainz, Germany

3 Faculty of Medicine, Institute and Policlinic of Occupational and Social Medicine, TU Dresden, Fetscherstr. 74, 01307 Dresden, Germany

4 Department of Psychosomatics and Health Behaviour, Norwegian Institute of Public Health, 0403 Oslo, Norway

5 FFAS, Freiburg Research Centre for Occupational and Social Medicine, Bertoldstr. 27, 79098 Freiburg, Germany

6 Department of General and Interventional Cardiology, University Heart Center Hamburg, Martinistr. 52, 20251 Hamburg, Germany

7 Department of Ophthalmology, University Medical Center Mainz, Johannes Gutenberg-Universität Mainz, Langenbeckstr. 1, 55131 Mainz, Germany a variety of lifestyle, and dispositional variables were enquired.

Results Night shift work was performed by 1071 out of 8065 currently employed individuals. The strongest association after adjustment for age, sex, job complexity level, being a manager, overtime work, and noise appeared for more than 660 night shifts within the last 10 years and a significantly increased arterial stiffness of $0.33 \mathrm{~m} / \mathrm{s}$. This reflects a $4 \%$ flow velocity increase for individuals with more than 660 night shifts compared to non-night workers. Regarding the entire professional life, night shift workers showed a significantly decreased vascular function by

8 Institute for Clinical Chemistry and Laboratory Medicine, University Medical Center, Johannes Gutenberg-Universität Mainz, Langenbeckstr. 1, 55131 Mainz, Germany

9 Department of Psychosomatic Medicine and Psychotherapy, University Medical Center Mainz, Johannes GutenbergUniversität Mainz, Langenbeckstr. 1, 55131 Mainz, Germany

10 Institute of Medical Biostatistics, Epidemiology and Informatics, University Medical Centre, Johannes Gutenberg-Universität Mainz, Obere Zahlbacher Straße 69, 55131 Mainz, Germany

11 DZHK (German Center for Cardiovascular Research), Partner Site Rhein-Main, Langenbeckstr. 1, 55131 Mainz, Germany

12 Center of Thrombosis and Hemostasis (CTH), University Medical Center Mainz, Langenbeckstr. 1, 55131 Mainz, Germany

13 Institute of Occupational, Social and Environmental Medicine, University Medical Center of the Johannes Gutenberg University Mainz, Obere Zahlbacher Straße 67, 55131 Mainz, Germany 
$-0.054 \mathrm{RH}$ index points by using the same adjustment. IMT values did not differ statistically from non-night workers. Lifestyle and dispositional factors showed an influence on all used subclinical atherosclerosis parameters.

Conclusions The cross-sectional results demonstrate an association between night work and detrimental changes in the atherosclerotic process. The association is more pronounced with more years in night shift and is partly explained by lifestyle and dispositional factors. Longitudinal analyses are necessary to confirm the results.

Keywords Night shift work · Arterial stiffness - Vascular function · Intima media thickness · Occupation · Population based

\section{Introduction}

Shift work is associated with circadian disruption, disturbs sleep and social life, and modifies disease risk factors (Puttonen et al. 2010; Ramin et al. 2015). Thus, shift work could potentially contribute to various chronic diseases including cardiovascular diseases (CVDs) (Frost et al. 2009; Wang et al. 2011). A considerable number of workers are concerned since the prevalence of shift work is estimated to range roughly between 15 and $20 \%$ across the EU and in the USA (Eurofound 2012; IARC 2010; Statistisches Bundesamt 2014).

Several studies have investigated the association between shift work and CVD. A meta-analysis (Vyas et al. 2012) confirms a modest association between shift work and myocardial infarction, describing a risk ratio of 1.23 [95\% confidence interval (CI) 1.15-1.31]. Night shift workers have been found to face the highest risk (risk ratio $1.41,95 \%$ CI 1.13-1.76). Shift work was not, however, associated with increased rates of mortality. The association of shift work and hypertension is still under debate (Esquirol et al. 2011). Some studies prove an association with the onset and progression of hypertension (e.g. de Bacquer et al. 2009; Kubo et al. 2013; Oishi et al. 2005).

Research to detect associations between shift work and cardiovascular health is challenging because of the long follow-up time that is needed to cover late outcomes such as myocardial morbidity (e.g. angina pectoris or myocardial infarction) or mortality. There may be a subsequent difficulty concerning a healthy worker effect since workers who cannot tolerate night work may change to day work.

One approach of tackling these issues is to include surrogate parameters that describe early subclinical changes in vascular structure and function, such as arterial stiffness, peripheral vascular function, or intima media thickness (IMT). The parameters differ both biologically regarding their potential for reversibility of the changes (e.g. after treatment), the interference with concurrent endogenous or exogenous factors (e.g. diurnal cycle), and methodologically regarding size and location of the blood vessel examined, as well as the type of measurement technique applied. Thus, it is important to measure both structural and functional outcomes because they may illuminate different mechanisms on the complex pathways to CVD [see (Puttonen et al. 2009)].

All of these surrogate parameters are discussed in recent publications as risk prediction markers of coronary events (Lorenz et al. 2012; Vlachopoulos et al. 2010; Yeboah et al. 2009). Yet, it remains uncertain to which extent the measurement of these markers adds to traditional instruments of risk prediction (de Ruijter et al. 2009), and whether the measures are independent or complementary (Lemos et al. 2015).

Measurements of selected subclinical parameters have been included in cross-sectional analyses on shift work (Chen et al. 2010; Kantermann et al. 2013; Suessenbacher et al. 2011) and one recent cohort study (Wang et al. 2015). So far, the stiffness index has only been investigated in one pilot study that considered exposure to shift work (Kantermann et al. 2013).

Against this background, we examined the association between night shift work and early cardiovascular markers in a population-based sample of employees from the baseline examination of the prospective Gutenberg Health Study (GHS). The objectives of these cross-sectional analyses were to investigate associations and dose-response relationships between (1) current and (2) cumulative exposure to night shift work and adverse effects on both structural (carotid IMT) and functional (arterial stiffness and peripheral vascular function) non-invasive parameters of subclinical atherosclerosis.

\section{Methods}

\section{Study population}

GHS is an ongoing single-centre population-based cohort study designed and conducted at the University Medical Centre in Mainz, Germany. Its main emphasis is placed on cardiovascular functioning and the improvement of vascular risk stratification (Wild et al. 2012). The sampling was based on 35- to 74-year-old residents of the City of Mainz and the district of Mainz-Bingen, randomly drawn and equally stratified by sex and residence for each decade of age. The baseline examinations were performed between 2007 and 2012 on 15,010 enroled persons. The 5-h-long examination included a variety of interviews, blood sampling, and clinical examinations. 
The recruitment efficacy proportion and the cooperation proportion in the baseline were 55.5 and $70.0 \%$, respectively (unpublished data).

For the purposes of these analyses, individuals were excluded who (1) were older than 64 years (retirement age) at the day of the interview $(n=3753)$, (2) did not provide any occupational information ( $n=57)$, or (3) stated to have never been employed in their lifetime (for at least 1 year in part-time); $(n=617)$. Out of the eligible 10,583 individuals between 35 and 64 years of age, complete information about confounders and covariates was available for 10,475 subjects included in the analyses. Subjects were either currently employed $(n=8065)$ or not working at present ( $n=2410 ; 23 \%$; e.g. unemployed, on parental leave, or in training).

Individuals with a self-reported diagnosis of CVD (i.e. coronary heart disease, myocardial infarction, stroke, or peripheral artery occlusive disease) were excluded in sensitivity analyses. To determine the influence of a history of cancer on the effects, sensitivity analyses were also conducted by additionally excluding individuals who reported a cancer diagnosis in the past.

\section{Definition of exposure}

Subjects were requested to specify every past occupational period including their occupational titles, as well as their current job. A maximum of 15 occupational periods could be covered within an interview. On average participants reported four periods. Within each of the occupational periods, the number of night shifts per month was enquired. Night shift work was defined as working hours between 11 p.m. and 5 a.m.

Based on this information, two main variables, current and cumulative night shift, were formed. The variable 'current night shift' was subdivided into a binary variable (night shift yes or no), and a numerical variable reflecting the number of current night shifts per month.

Cumulative night shifts were calculated in different steps. Within one occupational period, the reported number of night shifts per month was multiplied by eleven (since approximately 1 month of annual leave is standard in Germany) times the number of years in that period. Subsequently, the single periods spent with job tasks at night were summed up. The following final categorisation was used: 'no exposure' $=0$ nights, 'low exposure' $=1-220$ nights, 'medium exposure' $=221-660$ nights, and 'high exposure' $=$ more than 660 nights. The cut-off value of 220 equals the accumulation of one work year in night shift work (i.e. 250 annual working days -30 days of annual leave). The described categories of cumulative number of night shifts were considered for (a) the last 10 years, and (b) the entire working life.

\section{Outcomes}

The measurements used for investigations related to occupational exposures included arterial stiffness, vascular function, and IMT, bio-molecular examinations of fibrinogen and C-reactive protein, and clinical examinations (e.g. blood pressure, hypertension). For the present paper, the following early parameters of CVD were selected as outcomes in agreement with the GHS study protocol.

Arterial stiffness was measured as stiffness index examined by digital photoplethysmography (Pulse Trace PCA $2^{\mathrm{TM}}$, Micro Medical Ltd., currently CareFusion). The change in the volume pulse is registered via the pulsedependent absorption of infrared light (The Reference Values for Arterial Stiffness' Collaboration 2010). The stiffness index is measured in $\mathrm{m} / \mathrm{s}$ (body height/peak-to-peak time) and considered to be continuous. A high-flow velocity expresses inelastic (stiff) arterial blood vessels.

Vascular function of the resistance vessels is estimated by reactive hyperaemia index (RHI) that works as a continuous variable. The pulse amplitude was recorded by volume plethysmography with the non-invasive EndoPAT2000TM device (Itamar Medical, Caesarea, Israel) that detects plethysmographically pressure changes in the finger tips caused by the arterial pulse. After occlusion of the brachial artery, endothelium-mediated changes in vascular tone mirror the downstream hyperaemic response (Schnabel et al. 2011).

IMT was assessed by measuring the common carotid artery using Duplex ultrasound, realised with the iE33 system (Philips Medical Systems, Best, The Netherlands) (Sinning et al. 2011). The measurements of the right and left side (in $\mathrm{mm}$ ) were averaged. IMT was considered as a continuous variable.

The raw data of these subclinical parameters were evaluated by GHS physicians. Within the time frame of the project, evaluations of arterial stiffness were completed for the first 10,000 subjects; vascular function and IMT evaluations were completed for the first 5000 subjects. This resulted in a total number of valid arterial stiffness measurements for 7938 subjects, and likewise, there were $n=2387$ valid vascular function tests and $n=2508$ valid IMT measurements.

\section{Confounder and covariate selection}

Scientific evidence supporting the existence of the causal pathways between relevant potential confounders for night shift work and vascular outcomes was collected. Based upon this literature overview, relevant sets of confounders for night shift work and the cardiovascular outcomes were identified using acyclic directed graphs (Textor et al. 2011).

The following covariates were included block by block in the different regression models: 
(a) basic confounders (age and sex),

(b) current occupational exposures (job complexity level, supervisor/manager, overtime work, occupational noise), and

(c) lifestyle factors (smoking, alcohol, waist to hip ratio), SES, and dispositional factors (menopause status, family history of MI or stroke).

There is evidence to consider physical activity and vascular outcomes as confounders. Physical activity was not entered into model (c) because the recalculation to metabolic units based on the 66-item questionnaire Short QUestionnaire to ASsess Health-enhancing physical activity (SQUASH; (Campbell et al. 2016) was not finished at the time of the data analysis. Hypertension/blood pressure was not included as a confounder because it is assumed to lie on the biological pathway between shift work and the considered outcomes (Puttonen et al. 2010; Ramin et al. 2015).

Age and sex (a) were included in all models with age used in decades. Current occupational exposures (b) were coded based on the current job title and a short description of the employee's working tasks. For this purpose, the hierarchically structured system of the German Classification of Occupations 2010 (KldB 2010) was used (Prigge et al. 2014). The fifth digit of the KldB 2010 code represents four job complexity level: low (helpers), medium (skilled workers; used as a reference category), complex (specialists), and very complex (experts) requirements. The dichotomous variable of being a supervisor/manager, coded by the fourth KldB 2010-digit, reflects job position. Overtime work was assessed by the question 'On average, how many hours per week are you working overtime?', and was used continuously in hours. Occupational noise was inquired with a question whether the employee performs a job with high noise pollution (yes/no), followed by taking into account several noise sources $(1=$ refrigerator, ...., 5 = pneumatic hammer) to which the workplace's loudness level is best comparable. An affirmation of the binary request in combination with sound intensities that equal values between 3 and 5 was interpreted as being occupational noise exposed (secondary binary noise variable).

The included lifestyle factors (c) were smoking, alcohol, and waist to hip ratio. Smoking adjustment was based upon two concepts. The assignment smoking includes the categories 'never smoker', 'ex-smoker' with a quitting time of $<2$ years, 'ex-smoker' with a quitting time of more than 2 years, and 'current smoker'. To estimate pack-years, the smoking history was enquired including its duration and the type of tobaccos (filter tips, cigarettes, cigars, tobacco, and pipe). The three categories of ' $<20$ ', '20-39', and ' 40 or more pack-years' were used (Jha et al. 2013; van Amelsvoort et al. 2006). For alcohol consumption, the categories 'no alcohol intake', 'beneath tolerable limit', 'above tolerable limit', and 'abuse' were distinguished (Burger and Mensink 2003). Waist to hip ratio was differentiated into 'normal ratio', 'overweight', and 'obesity', according to WHO criteria (WHO 2000).

Menopause status was queried binary (yes/no). Socioeconomic status (SES) was used as an index score comprising school education, professional education, occupational position, and salary (Lampert and Kroll 2009). The scale ranges from 3 to 21 points. For the descriptive visualisation of the population, the empirically recommended cut points of $<7.8$ (low SES), 7.8-14 (intermediate SES), and $>14$ (high SES) were used (Lampert et al. 2013).

\section{Statistical analyses}

To describe the study population and the subclinical parameters, the following analyses were performed: for continuous variables, average values, standard deviations, medians, and quartiles were used and for categorical variables, number and percentage. The population was stratified by current night shift workers, employees without night shift work, and currently unemployed subjects. Stratification by sex was applied to describe details of night shift work. Analyses for cumulative night shift were based on the total sample, whereas only actively working subjects were considered regarding current night shift work $(n=8065)$.

Linear regression models were used to estimate the effect of current and cumulative night shift work on arterial stiffness (m/s), vascular function (index points), and IMT $(\mathrm{mm})$ by using generalised linear models with normal distribution and Wald statistics. The assumptions of a linear model were proved by visual control, tests on normal distribution, and correlation coefficients.

Based on the above-mentioned confounders and covariates, four different models were calculated for each outcome separately: an unadjusted, crude model (model 0); a basic model including adjustment for age and sex (model 1); a model including age and sex + occupational variables (model 2); and a model based on the adjustments of model 2 as well as of lifestyle, SES, and dispositional characteristics (model 3). The results will focus on model 2 as it contains the most relevant variables: Age and sex as well as occupational influences expressed by job complexity level, being a manager, overtime work, and noise. Model 3 will be considered as a conservative approach that covers influences of a broad spectrum, partly correcting for similar influences twice.

All variables within one confounder block were entered into the model simultaneously. The level of 'skilled workers' served as reference group and was contrasted to each of the three other complexity levels, respectively. Metric confounders and covariates were centred to ensure an interpretation of the intercept as an average level of the outcome at 
the centred values of the continuous independent variables (such as the centring of the variable age results in a value of 0 for a person aged 50). The analyses were performed by using the software R (R Core Team 2015).

For reasons of visualisation, based on the regression models, percentages of increase in arterial stiffness $(\mathrm{m} / \mathrm{s})$ were calculated for categories of night shift work exposure in the previous 10 years (exposed group) compared to the unexposed reference group by using the estimated beta coefficients and $95 \%$ CI. This was done by the following formula: (predicted value of the exposed group - the predicted value of the unexposed group) divided by the unexposed group times 100. The predicted values of the unexposed group for all outcomes (the intercepts) are provided in the 'Appendix'. Values of the exposed group are given in Table 1 . To estimate the dose-response relationship of cumulative night shift work and arterial stiffness, a post hoc linear trend test based on the results of the regression analyses was applied. This was performed by using the package 'generalised least squares for trend estimation of summarised dose-response data (glst)' within Stata ${ }^{\circledR} 13$ (Orsini et al. 2009).

\section{Results}

\section{Description of the study population}

Night shift work was performed by 1071 out of 8065 currently employed individuals with $7.6 \%$ of the women and $18 \%$ of the men operating nights. Table 1 characterises the sample population under investigation. It consists of current employed individuals (night shift workers and individuals without current night shift), currently unemployed subjects (e.g. unemployed, on parental leave, or in training), and the whole sample of ever employed subjects within the GHS working population.

Current night shift workers differed from those currently not working at night with regard to several characteristics: the percentage of males (74.2\%) was high, and night workers formed the group with the largest proportion of younger employees. The proportion of current night workers that were overweight slightly exceeded the fraction of those in day work as well as currently unemployed individuals. The highest proportion of current smokers $(29 \%)$ and heavy smokers (13\% had more than 20 pack-years) was also observed among subjects currently working at night. There are also differences between the groups according to SES (Table 1).

On average, within the individuals that work at night, both men and women carried out seven night shifts in the last month preceding the investigation. Typical sex differences surfaced particularly when cumulative night work exposure was considered. Within the last decade, men operated on average 116 nights, whereas women carried out an average of 53 nights shifts. Approximately the same sex divergence is true over the entire professional life with an average of 356 nights in shift work for men versus 151 night shifts for women. The sum of night shifts carried out over the active life equalled approximately the threefold number of the last 10 years.

The unadjusted distribution of subclinical parameters (Table 1) showed an elevated arterial stiffness for subjects operating at night compared to individuals without current night shift work. The RHI, describing vascular function, was lower in subjects currently working at night, thus pointing to an advanced atherosclerotic process in night shift workers. Similarly, numerically night shift workers had a slightly higher IMT compared to individuals not working between 11 p.m. and 5 a.m. Individuals without current employment showed numerically the most unfavourable values concerning IMT and arterial stiffness, whereas this was not the case for vascular function (Table 1).

\section{Current night shift}

Results of the linear regression analyses confirmed an effect of night shift in the current job on arterial stiffness with a significant increase of $0.02-0.06 \mathrm{~m} / \mathrm{s}$ per currently operated night (depending on the adjustment, Table 2). When applied to individuals with seven night shifts per months, this equals an increase of $0.21 \mathrm{~m} / \mathrm{s}(95 \%$ CI 0.07 $0.35 \mathrm{~m} / \mathrm{s}$ ) after adjustment for age and sex, job complexity level, being a manager, overtime work, and noise (model 2). Arterial stiffness increased by approximately $3 \%$.

An effect of working at night (yes vs. no) as well as of the number of nights spent working on the vascular function was not statistically significant after adjustment (Table 2; $p$ values for model $2 p=0.35$ for night shift work yes versus no and $p=0.27$ for the number of nights). As Table 2 shows, regression analyses did also not support relevant associations of current shift work and IMT.

\section{Cumulative night shift}

Results of the regression analyses showed an effect of cumulative night shift work on arterial stiffness. For the high exposure group with more than 660 night shifts, there were significant increases of 0.23 and $0.33 \mathrm{~m} / \mathrm{s}$ of arterial stiffness associated with cumulative exposure within the last 10 years (Table 3, model 2) and the entire professional life (Table 4, model 2). Compared to the average arterial stiffness of individuals without night shift work (the reference group), this reflects increases of 3 and $4 \%$, respectively. 
Table 1 Characteristics of current night shift workers, individuals without current night shift, currently unemployed subjects (e.g. unemployed, on parental leave, or in training), and the whole sam- ple of ever employed subjects within the working population of the Gutenberg Health Study $(n=10,475)$

\begin{tabular}{|c|c|c|c|c|}
\hline & $\begin{array}{l}\text { Current night shift } \\
(n=1071)\end{array}$ & $\begin{array}{l}\text { No current night shift } \\
(n=6994)\end{array}$ & $\begin{array}{l}\text { Currently unemployed } \\
(n=2410)\end{array}$ & Ever employed $(n=10,475)$ \\
\hline \multicolumn{5}{|l|}{ Sex } \\
\hline Males & $74.2 \%$ & $51.8 \%$ & $35.1 \%$ & $50.2 \%$ \\
\hline \multicolumn{5}{|l|}{ Age (years) } \\
\hline $35-44$ & $37.7 \%$ & $33.3 \%$ & $16.5 \%$ & $29.9 \%$ \\
\hline $45-54$ & $42.6 \%$ & $41.1 \%$ & $18.1 \%$ & $36.0 \%$ \\
\hline $55-64$ & $19.7 \%$ & $25.6 \%$ & $65.4 \%$ & $34.1 \%$ \\
\hline \multicolumn{5}{|l|}{ Waist hip ratio ${ }^{\mathrm{a}}$} \\
\hline Normal ratio & $17.3 \%$ & $19.6 \%$ & $12.7 \%$ & $17.8 \%$ \\
\hline Increased risk & $46.4 \%$ & $41.4 \%$ & $29.8 \%$ & $39.2 \%$ \\
\hline High risk & $36.4 \%$ & $39.0 \%$ & $57.5 \%$ & $43.0 \%$ \\
\hline \multicolumn{5}{|l|}{ Smoking status } \\
\hline Never & $38.1 \%$ & $44.2 \%$ & $43.8 \%$ & $43.4 \%$ \\
\hline $\begin{array}{l}\text { Ex-smoker }(0-2 \text { years } \\
\text { ago) }\end{array}$ & $3.6 \%$ & $2.6 \%$ & $2.0 \%$ & $2.6 \%$ \\
\hline Ex-smoker (>2 years ago) & $29.0 \%$ & $30.3 \%$ & $33.8 \%$ & $31.0 \%$ \\
\hline Current smoker & $29.2 \%$ & $22.9 \%$ & $20.4 \%$ & $23.0 \%$ \\
\hline \multicolumn{5}{|l|}{ Cumulative smoking } \\
\hline$<20$ pack-years & $46.6 \%$ & $44.6 \%$ & $44.6 \%$ & $44.8 \%$ \\
\hline 20-39 pack-years & $9.8 \%$ & $6.6 \%$ & $6.3 \%$ & $6.9 \%$ \\
\hline$>40$ pack-years & $3.3 \%$ & $2.4 \%$ & $3.5 \%$ & $2.8 \%$ \\
\hline \multicolumn{5}{|l|}{ Alcohol intake } \\
\hline No intake & $45.1 \%$ & $42.1 \%$ & $49.2 \%$ & $44.0 \%$ \\
\hline $\begin{array}{l}\text { Intake beneath tolerable } \\
\text { limit }^{\mathrm{b}}\end{array}$ & $31.6 \%$ & $31.2 \%$ & $25.1 \%$ & $29.9 \%$ \\
\hline $\begin{array}{l}\text { Intake above tolerable } \\
\text { limit }\end{array}$ & $20.2 \%$ & $24.2 \%$ & $22.3 \%$ & $23.4 \%$ \\
\hline Abuse of alcohol & $3.1 \%$ & $2.4 \%$ & $3.5 \%$ & $2.7 \%$ \\
\hline \multicolumn{5}{|l|}{ Socio-economic status } \\
\hline Low & $6.7 \%$ & $5.0 \%$ & $15.6 \%$ & $7.6 \%$ \\
\hline Intermediate & $53.6 \%$ & $48.4 \%$ & $62.0 \%$ & $52.1 \%$ \\
\hline High & $39.7 \%$ & $46.6 \%$ & $22.4 \%$ & $40.3 \%$ \\
\hline \multicolumn{5}{|l|}{ Subclinical parameters } \\
\hline $\begin{array}{l}\text { Arterial stiffness }(\mathrm{m} / \mathrm{s}) \\
\text { (median }[25 / 75 \text { quar- } \\
\text { tiles]) }\end{array}$ & $8.2(6.3 / 10.8)$ & $7.5(6.0 / 10.1)$ & $8.3(6.3 / 10.8)$ & $7.7(6.1 / 10.4)$ \\
\hline $\begin{array}{l}\text { Vascular function }{ }^{\mathrm{c}} \text { (mean } \\
\text { value }[\mathrm{SD}])\end{array}$ & $0.57(0.39)$ & $0.64(0.40)$ & $0.64(0.40)$ & $0.63(0.40)$ \\
\hline $\begin{array}{l}\text { Intima media thickness } \\
(\mathrm{mm}) \text { (median }[25 / 75 \\
\text { quartiles]) }\end{array}$ & $0.59(0.53 / 0.67)$ & $0.58(0.53 / 0.66)$ & $0.64(0.56 / 0.72)$ & $0.60(0.54 / 0.68)$ \\
\hline
\end{tabular}

${ }^{a}$ Limits for men: normal ratio $<0.9$; increased risk $\geq 0.9$ and $\leq 1$; high risk $>1$; limits for women: normal ratio $<0.8$; increased risk $\geq 0.8$ and $\leq 0.85$; high risk $>0.85$

${ }^{\mathrm{b}}$ Limits for men: beneath tolerable limit $\leq 20 \mathrm{~g} /$ day; above tolerable limit $>20-60 \mathrm{~g} /$ day; abuse $>60 \mathrm{~g} /$ day; limits for women: beneath tolerable limit $\leq 10$ g/day; above tolerable limit $>10-40$ g/day; abuse $>40$ g/day

c Reactive hyperaemia index (RHI)

Figure 1 depicts the relationship between cumulative night shift work within the last decade and arterial stiffness. Higher cumulative night shift exposures were associated with a more pronounced arterial stiffness. A dose-response relationship was indicated by a statistically confirmed increase only for the unadjusted model and shows a linear 
Table 2 Association of current night shift with subclinical atherosclerosis. Estimated beta coefficients for arterial stiffness, vascular function, and intima media thickness (95\% confidence interval) within the currently employed working population of the Gutenberg Health Study ( $n=8065$ subjects aged 35-64 years)

\begin{tabular}{|c|c|c|c|c|c|c|}
\hline \multirow[t]{4}{*}{ Exposure } & \multicolumn{6}{|c|}{ Marker of subclinical atherosclerosis (number of available measurements) } \\
\hline & \multicolumn{6}{|c|}{ Current night shift work } \\
\hline & \multicolumn{2}{|c|}{$\begin{array}{l}\text { Arterial stiffness }(n=5982) \text { effect esti- } \\
\text { mate: beta coefficient }(\mathrm{m} / \mathrm{s})\end{array}$} & \multicolumn{2}{|c|}{$\begin{array}{l}\text { Vascular function [reactive hyperaemia } \\
\text { index (RHI)] ( } n=1787) \text { effect estimate: } \\
\text { beta coefficient (index points) }\end{array}$} & \multicolumn{2}{|c|}{$\begin{array}{l}\text { Intima media thickness }(n=1868) \\
\text { effect estimate: beta coefficient }(\mathrm{mm})\end{array}$} \\
\hline & $\begin{array}{l}\text { Night shift yes } \\
\text { versus no }\end{array}$ & $\begin{array}{l}\text { Number of night } \\
\text { shifts per month }\end{array}$ & $\begin{array}{l}\text { Night shift yes } \\
\text { versus no }\end{array}$ & $\begin{array}{l}\text { Number of night } \\
\text { shifts per month }\end{array}$ & $\begin{array}{l}\text { Night shift yes } \\
\text { versus no }\end{array}$ & $\begin{array}{l}\text { Number of night } \\
\text { shifts per month }\end{array}$ \\
\hline $\begin{array}{l}\text { Model } 0 \\
\quad \text { unadjusted }\end{array}$ & $\begin{array}{l}0.45 \\
(0.25 / 0.66)\end{array}$ & $\begin{array}{l}0.06 \\
(0.04 / 0.09)\end{array}$ & $\begin{array}{l}-0.074 \\
(-0.127 /-0.022)\end{array}$ & $\begin{array}{l}-0.007 \\
(-0.013 /-0.001)\end{array}$ & $\begin{array}{l}-0.002 \\
(-0.016 / 0.012)\end{array}$ & $\begin{array}{l}0.000 \\
(-0.002 / 0.001)\end{array}$ \\
\hline Model $1^{\mathrm{a}}$ & $\begin{array}{l}0.17 \\
(-0.01 / 0.36)\end{array}$ & $\begin{array}{l}0.04 \\
(0.02 / 0.06)\end{array}$ & $\begin{array}{l}0.030 \\
(-0.081 / 0.020)\end{array}$ & $\begin{array}{l}-0.004 \\
(-0.009 / 0.002)\end{array}$ & $\begin{array}{l}0.004 \\
(-0.009 / 0.016)\end{array}$ & $\begin{array}{l}0.000 \\
(-0.001 / 0.001)\end{array}$ \\
\hline Model $2^{\mathrm{b}}$ & $\begin{array}{l}0.08 \\
(-0.10 / 0.26)\end{array}$ & $\begin{array}{l}0.03 \\
(0.01 / 0.05)\end{array}$ & $\begin{array}{l}-0.025 \\
(-0.076 / 0.027)\end{array}$ & $\begin{array}{l}-0.003 \\
(-0.009 / 0.003)\end{array}$ & $\begin{array}{l}0.002 \\
(-0.022 / 0.014)\end{array}$ & $\begin{array}{l}0.000 \\
(-0.002 / 0.001)\end{array}$ \\
\hline Model $3^{\mathrm{c}}$ & $\begin{array}{l}0.03 \\
(-0.15 / 0.21)\end{array}$ & $\begin{array}{l}0.02 \\
(0 / 0.04)\end{array}$ & $\begin{array}{l}-0.018 \\
(-0.068 / 0.033)\end{array}$ & $\begin{array}{l}-0.003 \\
(-0.009 / 0.003)\end{array}$ & $\begin{array}{l}0.000 \\
(-0.012 / 0.013)\end{array}$ & $\begin{array}{l}0.000 \\
(-0.002 / 0.001)\end{array}$ \\
\hline
\end{tabular}

a Model 1: adjusted for age and sex

${ }^{\mathrm{b}}$ Model 2: adjustments of model $1+$ occupational variables (+job complexity level, being a manager, overtime work, noise)

${ }^{c}$ Model 3: adjustments of model $2+$ socio-economic status, smoking status, pack-years, alcohol intake, waist to hip ratio, menopause status, and family history of myocardial infarction or stroke

Results in bold font indicate confidence intervals that do not contain the null hypothesis value

increase in the pulse wave velocity of $0.26 \mathrm{~m} / \mathrm{s}(0.39$ $4.89 \mathrm{~m} / \mathrm{s}$ ) per night shift work category.

For vascular function, significant decreases in the RHI were confirmed for exposures of 221-660 nights spent working within the last 10 years as well as for the highest exposure of night work within the active life ( $>660$ nights). This corresponds to a decrease in the RHI by approximately $12 \%$ per night shift work category for night shift workers compared with the estimated value for unexposed subjects.

Neither cumulative exposure to night shift work within the last 10 years nor throughout the entire work life was significantly associated with the IMT.

\section{Sensitivity analysis}

Neither the exclusion of subjects with a pre-existing CVD nor the additional exclusion of persons previously diagnosed with cancer had an effect on the results (data not shown).

\section{Discussion}

In summary, the presented analyses of the baseline data from a large population-based study show an impact of the cumulative number of night shifts throughout the entire professional life on the process of atherosclerosis as indicated by increased arterial stiffness and decreased vascular function. In addition, arterial stiffness was associated with cumulative number of night shifts within the last 10 years and with the number of current night shifts. However, no association was found between current and cumulative night shift exposure and an increased IMT.

Several possible causal mechanisms are described explaining the link between shift work, CVDs, and the preceding process of atherosclerosis: the hypotheses include circadian disruption, sleep deprivation, and social stress related to shift work, lifestyle changes (smoking, lack of physical activity), and low SES. Each of the above-mentioned mechanisms may operate differently (e.g. inflammatory processes, circadian disruption resulting in different functions of endothelial cells, and vascular smooth muscle cells) with respect to the investigated subclinical parameters arterial stiffness, vascular function, and IMT investigated in the GHS. This may contribute to the inconsistent results.

Within the three outcomes considered, arterial stiffness displayed both the strongest effects and a dose-response relationship with cumulative night shift work. Arterial stiffness is a functional marker with a very good reproducibility (Meyer et al. 2016). The underlying mechanisms for the null result regarding the association between night shift work and the structural parameter IMT are difficult to explain. In contrast to the other two subclinical markers considered, IMT was categorised and used as a binary variable. However, models with IMT as a continuous variable 


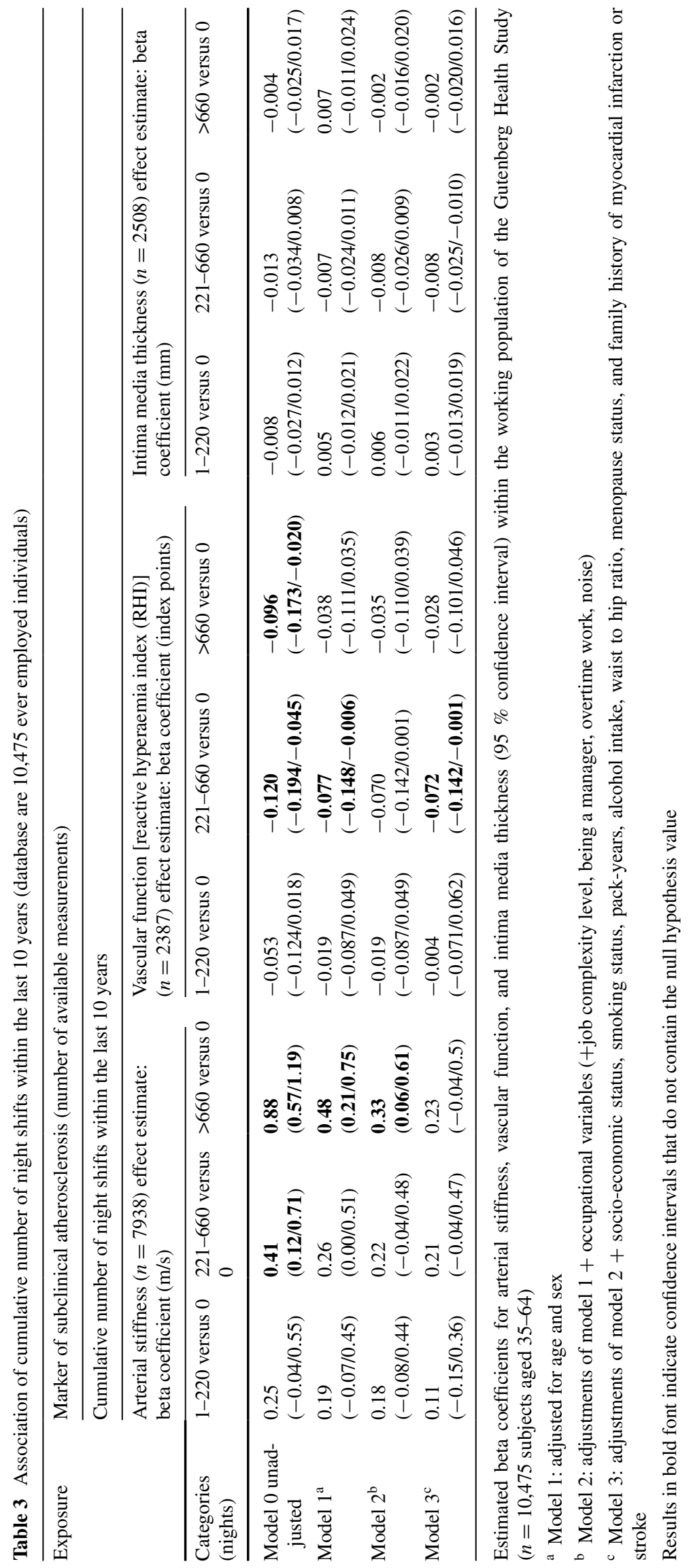




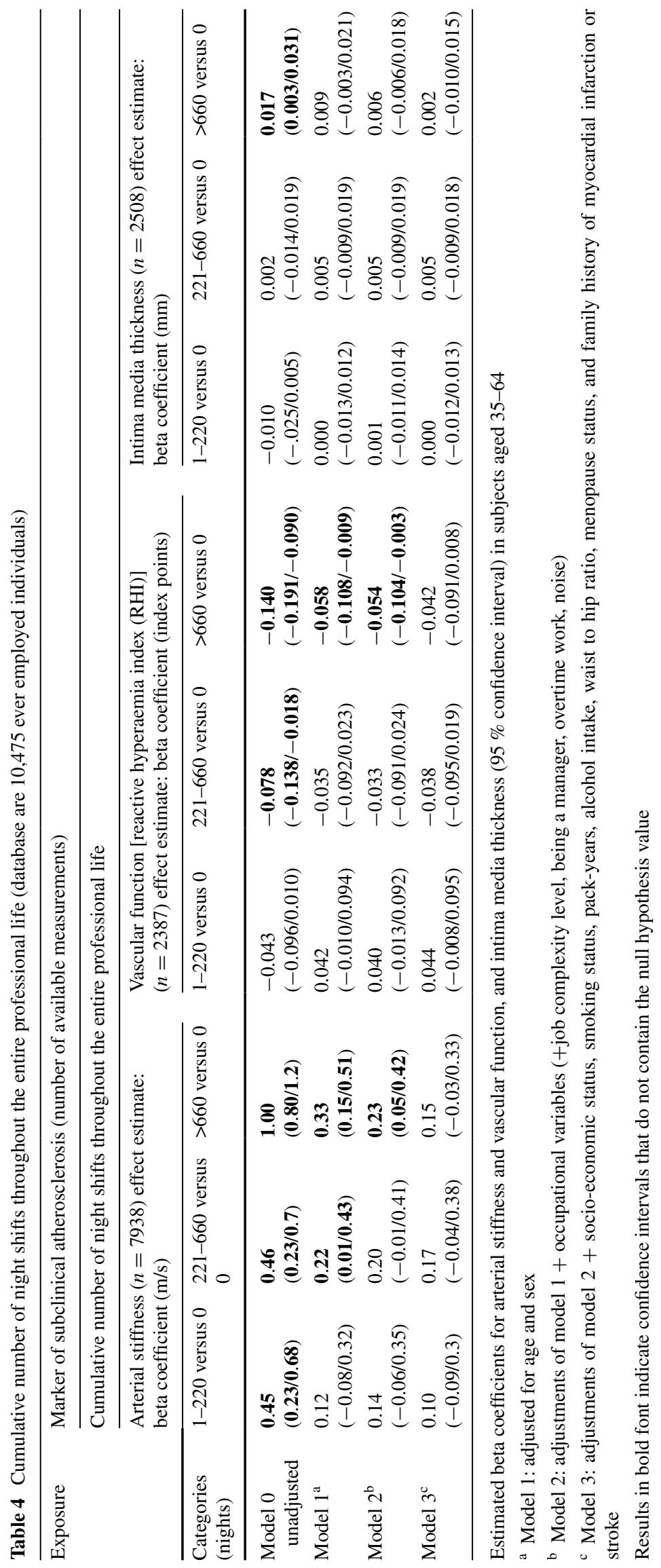


Fig. 1 Association between cumulative night shift work during the last 10 years and arterial stiffness (in four statistical models). Percentage change in arterial stiffness and $95 \%$ confidence intervals (CI) based on the ratio of subjects exposed to night shift and the unexposed reference group (basis of the comparisons: beta estimates $(\mathrm{m} / \mathrm{s})$ and $95 \% \mathrm{CI})$

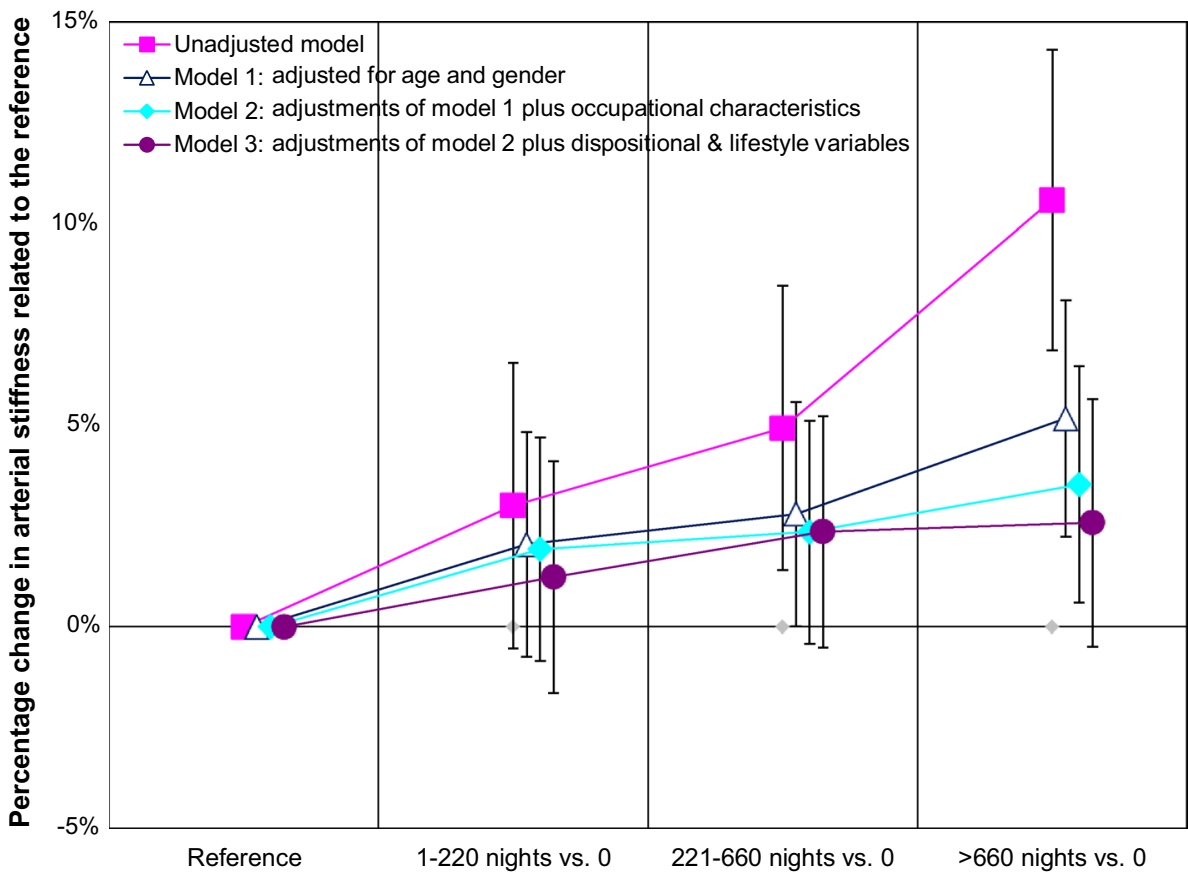

Cumulative night shift work in the last 10 years gave similar results (data not shown). One explanation is the large standard deviation of the measurement compared to arterial stiffness.

Furthermore, three points related to the exposure need to be taken into account for the interpretation of the results. First, in GHS, like in most population-based cohort studies on shift work, self-reported information on the occupational exposure without validation by objective company data is used. Second, the exposure under investigation was night shift requested as 'working between 11 p.m. and 5 a.m.'. This description of the exposure is distinct. On the other hand, it may give rise to misclassification, since employees with evening shift until 12 p.m. can be wrongly graded as night shift workers. Third, the unexposed reference group in the analyses on cumulative night shift exposure included a considerable percentage of persons with periods of unemployment. Currently, unemployed subjects within the study population were characterised by accumulated cardiovascular risk factors, such as higher age, a lower SES, and a higher number of subjects with obesity. This means a higher likelihood for the presence of atherosclerosis. Thus, the presented results obtained by regression analyses investigating the effect of cumulative night shift exposure should be rated as conservative.

Discrepancies between the results found with different statistical models may partly be explained by the inclusion of cardiovascular risk factors such as body proportion and smoking as covariates, which may rather be intermediate variables between shift work and CVDs, and thus attenuate the effect. Many studies support an association of shift work with changes in lifestyle factors such as weight gain (Amani and Gill 2013). Furthermore, night workers already smoke more before they enter into shift work (NabeNielsen et al. 2008). As smoking status and pack-years were not included in our main model, residual confounding cannot be ruled out. However, the association between current number of night shifts per month and arterial stiffness remained significant in the model that additionally controlled for lifestyle factors including smoking. In general, since covariates were not separately included into the models, but in blocks, a contribution of single mediating factors or confounders is difficult to conclude.

\section{Comparison with results described in the literature}

Measurements of the investigated subclinical markers have sporadically been included in investigations considering occupational exposures, but only few investigations consider the relation between shift work and these subclinical parameters.

\section{Arterial stiffness}

A pilot study investigating pulse wave velocity in relation to shift work in male steelworkers found no significant differences between day workers and shift workers with respect to arterial stiffness. However, there was a positive correlation between the individual shift workload (a measure including social jetlag, speed of shift work rotation, and years of shift work rotation) (Kantermann et al. 2013) and 
arterial stiffness. This indication of a dose-response relationship resembles the results of the present study. Also, an investigation of professional bus drivers exploring brachial ankle pulse wave velocity in shift drivers versus non-shift drivers found a higher pulse wave velocity in long-term shift drivers compared to regular and short-term shift drivers (Chen et al. 2010).

\section{Vascular function}

Vascular function in relation to shift work was considered in several small-scale studies investigating different occupational groups, particularly medical staff, by applying different techniques. Despite the different techniques, all results support an association of shift work with impaired vascular function. The presented analyses from a large populationbased study are generally in line with these results. The inconsistencies within the present results may be due to a smaller sample size, leading to a loss of power. Estimates may fail to reach statistical significance as compared with the presented analyses of arterial stiffness. Yet, the sample size for analyses of vascular function of the current GHS study exceeds those included in previous studies. A study investigating healthy medical residents, without any cardiovascular risk factor, found slightly impaired flow-mediated dilation (FMD) after a working night compared to a restful night (Tarzia et al. 2012). Amir et al. (2004) reported an abnormal brachial artery endothelial function in residents and house staff after a 24-h shift, including night duty and described dose-response relationships: the largest decrease in FMD was observed in physicians with a longer history of night shift duty and in those reporting fewer sleeping hours during the shift. Also, results of the GHS show the most distinct change in vascular function in the group of employees who had the highest shift work exposure considering their total working life. Suessenbacher et al. (2011) investigated 48 male shift workers and 47 male non-shift workers of a glass manufactory and indicated a reduced vascular function. Dispatchers in shift work exhibited reduced vascular functioning (Wong et al. 2012).

\section{Intima media thickness}

In contrast to arterial stiffness and vascular function, the presented analyses did not show a relation between shift work exposure and an increase in the IMT after adjustment.

However, results from the literature are ambiguous. A cross-sectional study by Haupt et al. (2008) describes a higher atherosclerotic risk in shift workers aged at least 45 years showing an increased IMT within a logistic (instead of a linear) model. Results of the Cardiovascular Risk in Young Finns study (Puttonen et al. 2009) also suggest that shift work is associated with an increased IMT observable in men already before age 40, but not in women. The prospective Kuopio Ischaemic Heart Disease Risk Factor Study (Wang et al. 2015) investigated the relationship between different work schedules and the 11-year progression of carotid atherosclerosis indicating that weekend shifts, more than standard daytime work, appear to accelerate carotid atherosclerosis progression among middleaged Finnish men, especially those with pre-existing CVD. However, no substantial difference in IMT increase was found when comparing employees who did evening/night or rotating shifts with standard daytime workers.

\section{Limitations and strengths}

The following limitations of the presented cross-sectional analysis of the GHS baseline need to be mentioned. Information about features of shift work was lacking (e.g. shift type, direction of rotation). Thus, the inquiry implies a risk for misclassification as already discussed. All information about shift work is based on retrospective self-assessments. The number of valid measurements of vascular function and IMT was limited for this baseline analysis. Therefore, the statistical power to detect effects of different levels of exposure to night shift work on these subclinical markers was reduced. It was not possible to take into account physical activity. The longitudinal analyses will consider physical activity as a potential confounder.

Several characteristics of this study are notably. Compared to the results from the literature discussed above, the number of participants investigated in the GHS is large, including different age groups of the working population as well as a variety of occupations. Information about cumulative night shift exposure based on a comprehensive occupational history was included. Additionally, three subclinical parameters have been investigated and measured with highly standardised procedures and quality control. To our knowledge, this is the first population-based study on shift work and arterial stiffness and endothelial function, respectively.

\section{Implications for further research}

The presented results from the baseline of a large prospective cohort study (GHS) investigating several risk factors with respect to cardiovascular health indicate an effect of cumulative night shift work on the atherosclerotic process looking retrospectively on the number of night shifts during professional life. Further longitudinal analyses projected within the design of the GHS are necessary to confirm these results by taking into account a priori defined levels of clinically important changes in the investigated parameters during follow-up. The results also provide evidence for the potential usefulness of these 
earlier subclinical markers as outcomes in epidemiological studies on occupational cardiovascular health. Possible associations are usually examined considering incident myocardial infarction-an outcome which takes many years to develop. Future studies on cardiovascular risks of shift work could be improved with a more differentiated assessment of working time (e.g. shift intensity, length of working hours) and subclinical atherosclerosis as suggested by Härmä et al. (2015). In particular, further research is needed on the effectiveness of interventions in work organisation, e.g. changing shift rosters could be monitored by the parameters used in the present study.

Hypertension may be on the biological pathway from shift work to atherosclerosis (Puttonen et al. 2010) and was therefore not considered as a confounder. When we excluded all subjects with a self-reported diagnosis of CVD in a sensitivity analysis, the results were similar (data not shown). Future studies might wish to study the effect of shift work on atherosclerosis independent of hypertension.

\section{Implications for occupational health practitioners}

This study indicates an increased risk of atherosclerosis in long-term night shift workers, making them a potential target group for health promotion and surveillance, including preventive medical examinations to detect early signs of CVD. It seems reasonable to integrate arterial stiffness or the measurement of vascular function in these medical

Table 5 Intercept values of unexposed participants to complement Table 2: arterial stiffness $(\mathrm{m} / \mathrm{s})$, vascular function (index points), and intima media thickness (mm) with $95 \%$ confidence interval (CI) of examinations to monitor the atherosclerotic process in order to better assess the demanding effect of night shift work.

Acknowledgments The Gutenberg Health Study is funded through the government of Rheinland-Pfalz ('Stiftung Rheinland-Pfalz für Innovation', Contract AZ 961-386261/733), the research programs 'Wissenschaft Zukunft' and 'Schwerpunkt Vaskuläre Prävention' of the Johannes Gutenberg University of Mainz, and its contract with Boehringer Ingelheim and PHILIPS Medical Systems, including an unrestricted grant for the Gutenberg Health Study. Philipp S Wild is funded by the Federal Ministry of Education and Research (BMBF 01EO1003). The Federal Institute for Occupational Safety and Health (BAuA) financed the collection of occupational variables within the GHS and this analysis (BAuA research Project No. F2235). All authors approved the final manuscript.

\section{Compliance with ethical standards}

Conflict of interest The authors declare that they have no conflict of interest.Open Access This article is distributed under the terms of the Creative Commons Attribution 4.0 International License (http:// creativecommons.org/licenses/by/4.0/), which permits unrestricted use, distribution, and reproduction in any medium, provided you give appropriate credit to the original author(s) and the source, provide a link to the Creative Commons license, and indicate if changes were made.

\section{Appendix}

\section{See Tables 5, 6 and 7.}

currently employed subjects without current shift work of the Gutenberg Health Study ( $n=8065$ subjects aged 35-64 years)

\begin{tabular}{|c|c|c|c|c|c|c|}
\hline \multirow[t]{4}{*}{ Exposure } & \multicolumn{6}{|c|}{ Marker of subclinical atherosclerosis (number of available measurements) } \\
\hline & \multicolumn{6}{|c|}{ Not exposed: no current night shift work } \\
\hline & \multicolumn{2}{|c|}{$\begin{array}{l}\text { Arterial stiffness }(n=5982) \text { intercept } \\
(\mathrm{m} / \mathrm{s})\end{array}$} & \multicolumn{2}{|c|}{$\begin{array}{l}\text { Vascular function [reactive hyperaemia } \\
\text { index (RHI)] }(n=1787) \text { intercept } \\
\text { (index points) }\end{array}$} & \multicolumn{2}{|c|}{$\begin{array}{l}\text { Intima media thickness }(n=1868) \\
\text { intercept }(\mathrm{mm})\end{array}$} \\
\hline & $\begin{array}{l}\text { Night shift yes } \\
\text { versus no }\end{array}$ & $\begin{array}{l}\text { Number of night } \\
\text { shifts per month }\end{array}$ & $\begin{array}{l}\text { Night shift yes } \\
\text { versus no }\end{array}$ & $\begin{array}{l}\text { Number of night } \\
\text { shifts per month }\end{array}$ & $\begin{array}{l}\text { Night shift yes } \\
\text { versus no }\end{array}$ & $\begin{array}{l}\text { Number of night } \\
\text { shifts per month }\end{array}$ \\
\hline $\begin{array}{l}\text { Model } 0 \\
\quad \text { unadjusted }\end{array}$ & $\begin{array}{l}8.22 \\
(8.14 / 8.29)\end{array}$ & $\begin{array}{l}8.28 \\
(8.21 / 8.35)\end{array}$ & $\begin{array}{l}0.638 \\
(0.619 / 0.658)\end{array}$ & $\begin{array}{l}0.628 \\
(0.609 / 0.646)\end{array}$ & $\begin{array}{l}0.602 \\
(0.597 / 0.608)\end{array}$ & $\begin{array}{l}0.602 \\
(0.597 / 0.607)\end{array}$ \\
\hline Model $1^{\mathrm{a}}$ & $\begin{array}{l}9.08 \\
(8.99 / 9.17)\end{array}$ & $\begin{array}{l}9.11 \\
(9.02 / 9.19)\end{array}$ & $\begin{array}{l}0.522 \\
(0.497 / 0.547)\end{array}$ & $\begin{array}{l}0.517 \\
(0.494 / 0.541)\end{array}$ & $\begin{array}{l}0.610 \\
(0.604 / 0.616)\end{array}$ & $\begin{array}{l}0.611 \\
(0.605 / 0.617)\end{array}$ \\
\hline Model $2^{\mathrm{b}}$ & $\begin{array}{l}9.16 \\
(9.03 / 9.29)\end{array}$ & $\begin{array}{l}9.16 \\
(9.04 / 9.29)\end{array}$ & $\begin{array}{l}0.511 \\
(0.474 / 0.548)\end{array}$ & $\begin{array}{l}0.508 \\
(0.472 / 0.544)\end{array}$ & $\begin{array}{l}0.619 \\
(0.611 / 0.621)\end{array}$ & $\begin{array}{l}0.620 \\
(0.611 / 0.628)\end{array}$ \\
\hline Model $3^{\mathrm{c}}$ & $\begin{array}{l}8.66 \\
(8.49 / 8.83)\end{array}$ & $\begin{array}{l}8.66 \\
(8.50 / 8.83)\end{array}$ & $\begin{array}{l}0.592 \\
(0.543 / 0.640)\end{array}$ & $\begin{array}{l}0.590 \\
(0.542 / 0.638)\end{array}$ & $\begin{array}{l}0.608 \\
(0.697 / 0.620)\end{array}$ & $\begin{array}{l}0.609 \\
(0.697 / 0.620)\end{array}$ \\
\hline
\end{tabular}

a Model 1: adjusted for age and sex

b Model 2: adjustments of model $1+$ occupational variables (+job complexity level, being a manager, overtime work, noise)

c Model 3: adjustments of model 2 + socio-economic status, smoking status, pack-years, alcohol intake, waist to hip ratio, menopause status, and family history of myocardial infarction or stroke 
Table 6 Intercept values of unexposed participants to complement Table 3: arterial stiffness $(\mathrm{m} / \mathrm{s})$, vascular function (index points), and intima media thickness $(\mathrm{mm})$ with $95 \%$ confidence interval $(\mathrm{CI})$ of subjects without current shift work within the last 10 years across the 10,475 ever employed individuals aged 35-64 of the Gutenberg Health Study

\begin{tabular}{|c|c|c|c|}
\hline \multirow[t]{3}{*}{ Exposure } & \multicolumn{3}{|c|}{ Marker of subclinical atherosclerosis (number of available measurements) } \\
\hline & \multicolumn{3}{|c|}{ Not exposed: no night shift work within the last 10 years } \\
\hline & $\begin{array}{l}\text { Arterial stiffness }(n=7938) \text { intercept } \\
(\mathrm{m} / \mathrm{s})\end{array}$ & $\begin{array}{l}\text { Vascular function [reactive hyperaemia } \\
\text { index }(\mathrm{RHI})](n=2387) \text { intercept (index } \\
\text { points) }\end{array}$ & $\begin{array}{l}\text { Intima media thickness }(n=2508) \\
\text { intercept }(\mathrm{mm})\end{array}$ \\
\hline Model 0 unadjusted & $\begin{array}{l}8.31 \\
(8.24 / 8.37)\end{array}$ & $\begin{array}{l}0.640 \\
(0.623 / 0.657)\end{array}$ & $\begin{array}{l}0.616 \\
(0.611 / 0.621)\end{array}$ \\
\hline Model $1^{\mathrm{a}}$ & $\begin{array}{l}9.29 \\
(9.21 / 9.37)\end{array}$ & $\begin{array}{l}0.514 \\
(0.491 / 0.537)\end{array}$ & $\begin{array}{l}0.626 \\
(0.621 / 0.632)\end{array}$ \\
\hline Model $2^{\mathrm{b}}$ & $\begin{array}{l}9.35 \\
(9.25 / 9.46)\end{array}$ & $\begin{array}{l}0.496 \\
(0.466 / 0.526)\end{array}$ & $\begin{array}{l}0.632 \\
(0.625 / 0.640)\end{array}$ \\
\hline Model $3^{\mathrm{c}}$ & $\begin{array}{l}8.88 \\
(8.74 / 9.02)\end{array}$ & $\begin{array}{l}0.580 \\
(0.539 / 0.620)\end{array}$ & $\begin{array}{l}0.619 \\
(0.609 / 0.629)\end{array}$ \\
\hline
\end{tabular}

a Model 1: adjusted for age and sex

b Model 2: adjustments of model $1+$ occupational variables (+job complexity level, being a manager, overtime work, noise)

c Model 3: adjustments of model 2 + socio-economic status, smoking status, pack-years, alcohol intake, waist to hip ratio, menopause status, and family history of myocardial infarction or stroke

Table 7 Intercept values of unexposed participants to complement Table 4: arterial stiffness $(\mathrm{m} / \mathrm{s})$, vascular function (index points), and intima media thickness with (95\% confidence interval) of sub- jects without current shift work throughout the entire professional life across the 10,475 ever employed individuals aged 35-64 of the Gutenberg Health Study

\begin{tabular}{|c|c|c|c|}
\hline \multirow[t]{3}{*}{ Exposure } & \multicolumn{3}{|c|}{ Marker of subclinical atherosclerosis (number of available measurements) } \\
\hline & \multicolumn{3}{|c|}{ Not exposed: no night shift work throughout the entire professional life } \\
\hline & $\begin{array}{l}\text { Arterial stiffness }(n=7938) \text { intercept } \\
(\mathrm{m} / \mathrm{s})\end{array}$ & $\begin{array}{l}\text { Vascular function [reactive hyperaemia } \\
\text { index }(\mathrm{RHI})](n=2387) \text { intercept } \\
\text { (index points) }\end{array}$ & $\begin{array}{l}\text { Intima media thickness }(n=2508) \\
\text { intercept }(\mathrm{mm})\end{array}$ \\
\hline Model 0 unadjusted & $\begin{array}{l}8.20 \\
(8.13 / 8.27)\end{array}$ & $\begin{array}{l}0.654 \\
(0.635 / 0.672)\end{array}$ & $\begin{array}{l}0.614 \\
(0.608 / 0.619)\end{array}$ \\
\hline Model $1^{\mathrm{a}}$ & $\begin{array}{l}9.26 \\
(9.17 / 9.35)\end{array}$ & $\begin{array}{l}0.511 \\
(0.485 / 0.537)\end{array}$ & $\begin{array}{l}0.625 \\
(0.618 / 0.631)\end{array}$ \\
\hline Model $2^{\mathrm{b}}$ & $\begin{array}{l}9.33 \\
(9.22 / 9.44)\end{array}$ & $\begin{array}{l}0.496 \\
(0.464 / 0.528)\end{array}$ & $\begin{array}{l}0.631 \\
(0.623 / 0.639)\end{array}$ \\
\hline Model $3^{c}$ & $\begin{array}{l}8.86 \\
(8.72 / 9.01)\end{array}$ & $\begin{array}{l}0.578 \\
(0.537 / 0.620)\end{array}$ & $\begin{array}{l}0.618 \\
(0.607 / 0.628)\end{array}$ \\
\hline
\end{tabular}

a Model 1: adjusted for age and sex

b Model 2: adjustments of model $1+$ occupational variables (+job complexity level, being a manager, overtime work, noise)

${ }^{c}$ Model 3: adjustments of model 2 + socio-economic status, smoking status, pack-years, alcohol intake, waist to hip ratio, menopause status, and family history of myocardial infarction or stroke

\section{References}

Amani R, Gill T (2013) Shiftworking, nutrition and obesity: implications for workforce health-a systematic review. Asia Pac J Clin Nutr 22(4):505-515

Amir O, Alroy S, Schliamser JE et al (2004) Brachial artery endothelial function in residents and fellows working night shifts. Am J Cardiol 93(7):947-949

Burger M, Mensink G (2003) Bundesgesundheitssurvey: AlkoholKonsumverhalten in Deutschland. Robert Koch-Institut (RKI), Berlin
Campbell N, Gaston A, Gray C, Rush E, Maddison R, Prapavessis H (2016) The Short QUestionnaire to ASsess Health-enhancing (SQUASH) physical activity in adolescents: a validation using doubly labeled water. J Phys Act Health 13(2):154-158

Chen CC, Shiu LJ, Li YL et al (2010) Shift work and arteriosclerosis risk in professional bus drivers. Ann Epidemiol 20(1):60-66

de Bacquer D, van Risseghem M, Clays E, Kittel F, de Backer G, Braeckman L (2009) Rotating shift work and the metabolic syndrome: a prospective study. Int J Epidemiol 38(3):848-854

de Ruijter W, Westendorp RG, Assendelft WJ et al (2009) Use of Framingham risk score and new biomarkers to predict 
cardiovascular mortality in older people: population based observational cohort study. BMJ 338:a3083

Esquirol Y, Perret B, Ruidavets JB et al (2011) Shift work and cardiovascular risk factors: new knowledge from the past decade. Arch Cardiovasc Dis 104(12):636-668

Eurofound (2012) Fifth European working conditions survey. Publications Office of the European Union, Luxembourg

Frost P, Kolstad HA, Bonde JP (2009) Shift work and the risk of ischemic heart disease-a systematic review of the epidemiologic evidence. Scand J Work Environ Health 35(3):163-179

Härmä M, Ropponen A, Hakola T et al (2015) Developing registerbased measures for assessment of working time patterns for epidemiologic studies. Scand J Work Environ Health 41(3):268-279

Haupt CM, Alte D, Dorr M et al (2008) The relation of exposure to shift work with atherosclerosis and myocardial infarction in a general population. Atherosclerosis 201(1):205-211

IARC (2010) Working Group on the evaluation of carcinogenic risks to humans: painting, firefighting, and shiftwork. IARC Monogr Eval Carcinog Risks Hum 98:9-764

Jha P, Ramasundarahettige C, Landsman V et al (2013) 21st-century hazards of smoking and benefits of cessation in the United States. N Engl J Med 368(4):341-350

Kantermann T, Duboutay F, Haubruge D, Kerkhofs M, SchmidtTrucksass A, Skene DJ (2013) Atherosclerotic risk and social jetlag in rotating shift-workers: first evidence from a pilot study. Work 46(3):273-282

Kubo T, Fujino Y, Nakamura T et al (2013) An industry-based cohort study of the association between weight gain and hypertension risk among rotating shift workers. J Occup Environ Med 55(9):1041-1045

Lampert T, Kroll LE (2009) Die Messung des sozioökonomischen Status in sozialepidemiologischen Studien. In: Richter M, Hurrelmann K (eds) Gesundheitliche Ungleichheit. VS Verlag für Sozialwissenschaften, Wiesbaden, pp 309-334

Lampert T, Kroll L, Muters S, Stolzenberg H (2013) Measurement of socioeconomic status in the German Health Interview and Examination Survey for Adults (DEGS1). Bundesgesundheitsblatt Gesundheitsforschung Gesundheitsschutz 56(5-6):631-636

Lemos SP, Passos VM, Brant LC, Bensenor IJ, Ribeiro AL, Barreto SM (2015) Inconsistent correlation between carotid artery intima-media thickness and peripheral arterial tonometry: Brazilian longitudinal study of adult health (ELSA-Brasil). Medicine 94(33):e1403

Lorenz MW, Polak JF, Kavousi M et al (2012) Carotid intimamedia thickness progression to predict cardiovascular events in the general population (the PROG-IMT collaborative project): a meta-analysis of individual participant data. Lancet 379(9831):2053-2062

Meyer ML, Tanaka H, Palta P et al (2016) Repeatability of central and peripheral pulse wave velocity measures: the atherosclerosis risk in communities (ARIC) study. Am J Hypertens 29(4):470-475

Nabe-Nielsen K, Garde AH, Tüchsen F, Hogh A, Diderichsen F (2008) Cardiovascular risk factors and primary selection into shift work. Scand J Work Environ Health 34(3):206-212

Oishi M, Suwazono Y, Sakata K et al (2005) A longitudinal study on the relationship between shift work and the progression of hypertension in male Japanese workers. J Hypertens 23(12):2173-2178

Orsini N, Bellocco R, Greenland S (2009) Generalized least square for trend estimation of summarized dose-response date. In: Sterne JA, Newton HJ, Cox NJ (eds) Meta-analysis in Stata: an updated collection from the Stata journal. Stata Press, College Station, pp 200-217

Prigge M, Köhr M, Pfeiffer N et al (2014) Codierung der Tätigkeitsangaben im Basiskollektiv der Gutenberg-Gesundheitsstudie unter Anwendung der Klassifikation der Berufe KldB
2010 — Darstellung des Vorgehens und der Datenqualität. Z Arbeitswissenschaft 68(3):153-161

Puttonen S, Kivimaki M, Elovainio M et al (2009) Shift work in young adults and carotid artery intima-media thickness: the Cardiovascular Risk in Young Finns study. Atherosclerosis 205(2):608-613

Puttonen S, Härmä M, Hublin C (2010) Shift work and cardiovascular disease-pathways from circadian stress to morbidity. Scand J Work Environ Health 36(2):96-108

R Core Team (2015) R: a language and environment for statistical computing. R Foundation for Statistical Computing, Vienna

Ramin C, Devore EE, Wang W, Pierre-Paul J, Wegrzyn LR, Schernhammer ES (2015) Night shift work at specific age ranges and chronic disease risk factors. Occup Environ Med 72(2):100-107

Schnabel RB, Schulz A, Wild PS et al (2011) Noninvasive vascular function measurement in the community: cross-sectional relations and comparison of methods. Circ Cardiovasc Imaging 4(4):371-380

Sinning C, Wild PS, Echevarria FM et al (2011) Sex differences in early carotid atherosclerosis (from the community-based Gutenberg-Heart Study). Am J Cardiol 107(12):1841-1847

Statistisches Bundesamt (2014) Bevölkerung und ErwerbstätigkeitErgebnisse des Mikrozensus 2013. Statistisches Bundesamt, Wiesbaden

Suessenbacher A, Potocnik M, Dorler J et al (2011) Comparison of peripheral endothelial function in shift versus nonshift workers. Am J Cardiol 107(6):945-948

Tarzia P, Milo M, Di Franco A et al (2012) Effect of shift work on endothelial function in young cardiology trainees. Eur J Prev Cardiol 19(5):908-913

Textor J, Hardt J, Knüppel S (2011) DAGitty: a graphical tool for analyzing causal diagrams. Epidemiology 22(5):745

The Reference Values for Arterial Stiffness' Collaboration (2010) Determinants of pulse wave velocity in healthy people and in the presence of cardiovascular risk factors: 'establishing normal and reference values'. Eur Heart J 31(19):2338-2350

van Amelsvoort LG, Jansen NW, Kant I (2006) Smoking among shift workers: more than a confounding factor. Chronobiol Int 23(6): 1105-1113

Vlachopoulos C, Aznaouridis K, Stefanadis C (2010) Prediction of cardiovascular events and all-cause mortality with arterial stiffness: a systematic review and meta-analysis. J Am Coll Cardiol 55(13):1318-1327

Vyas MV, Garg AX, Iansavichus AV et al (2012) Shift work and vascular events: systematic review and meta-analysis. BMJ 345:e4800

Wang XS, Armstrong ME, Cairns BJ, Key TJ, Travis RC (2011) Shift work and chronic disease: the epidemiological evidence. Occup Med 61(2):78-89

Wang A, Arah OA, Kauhanen J, Krause N (2015) Work schedules and 11-year progression of carotid atherosclerosis in middle-aged Finnish men. Am J Ind Med 58(1):1-13

WHO (2000) Obesity: preventing and managing the global epidemic. Technical Report Series No. 894. World Health Organization, Geneva

Wild PS, Zeller T, Beutel M et al (2012) The Gutenberg Health Study. Bundesgesundheitsblatt Gesundheitsforschung Gesundheitsschutz 55(6-7):824-829

Wong IS, Ostry AS, Demers PA, Davies HW (2012) Job strain and shift work influences on biomarkers and subclinical heart disease indicators: a pilot study. J Occup Environ Hyg 9(8):467-477

Yeboah J, Folsom AR, Burke GL et al (2009) Predictive value of brachial flow-mediated dilation for incident cardiovascular events in a population-based study: the multi-ethnic study of atherosclerosis. Circulation 120(6):502-509 